\title{
Oxidation studies of a novel peptide model
}

\section{$N$-acetyl-3-(methylthio)propylamine}

Tomasz Pedzinski, ${ }^{* 1,2}$ Franciszek Kazmierczak, ${ }^{1}$ Piotr Filipiak, ${ }^{1}$ Bronislaw Marciniak $^{1}$

${ }^{1}$ Faculty of Chemistry, Adam Mickiewicz University, $89 b$ Umultowska Str., 61-614 Poznan, Poland

${ }^{2}$ Adam Mickiewicz University Center for Advanced Technologies, 89c Umultowska Str., 61-614 Poznan, Poland

* corresponding author 


\section{Oxidation studies of a novel peptide model}

\section{$N$-acetyl-3-(methylthio)propylamine}

The ${ }^{\bullet} \mathrm{OH}$ radical induced oxidation of a selected methionine analogue $-N$-acetyl-3(methylthio)propylamine ( $N$-acetylated methionine without its carboxylic group) was investigated in aqueous solution. The oxidized intermediate $\left(>S^{\bullet+}\right)$ can be stabilized by the formation of two-centered three-electron bonds with electron-rich atoms $(\mathrm{S}, \mathrm{N}, \mathrm{O})$, or it can undergo deprotonation yielding the long-lived, carbon-centered $\alpha$-(alkylthio)alkyl radical $(\alpha \mathrm{S})$. The paths and kinetics of these reactions were followed using the pulse radiolysis technique with spectrophotometric detection. The reaction mechanism is shown to be different from the mechanism previously reported for 3(methylthio)propylamine (3-MTPA), and depends strongly on the structural nature of the methionine substituents.

The oxidation of 3 -AcMTPA by ${ }^{\bullet} \mathrm{OH}$ radicals in anaerobic conditions yielded a sulfoxide $(>\mathrm{S}=\mathrm{O})$ and a stable dimer $(\alpha \mathrm{S}-\alpha \mathrm{S})$ formed from the combination of two $\alpha$-(alkylthio)alkyl radicals as major stable products. The proposed mechanism is further supported by the stable product analysis carried out using a high-resolution LC-MS/MS technique. A detailed mechanism involving characterizations of the transients and the stable products is discussed in qualitative terms. It is clearly demonstrated that the results from the time-resolved investigations are consistent with the findings from the stable product analysis.

Keywords: methionine oxidation, three-electron bonds, pulse radiolysis 


\section{Introduction}

The oxidation mechanisms of amino acids and peptides have been investigated mainly due to the biological significance of such reactions [1]. One of the sites primarily attacked by oxidative agents such as free radicals, reactive oxygen species or short-lived excited states is the thioether function of a methionine (Met) residue. The Met oxidation can cause serious consequences during oxidative stress [1,2], however, despite the numerous studies focused on the one-electron oxidation processes of the methionine residue, some aspects of the process still remain unclear or controversial (e.g., the fate of free radicals leading to stable modifications of amino acids or the structure of the radical transients upon oxidation $[3,4]$ ). One-electron oxidation of Met-containing peptides and proteins in solution occurs easily e.g., by using the strongly oxidizing hydroxyl radicals $\left({ }^{\bullet} \mathrm{OH}\right)\left(E^{\circ}=1.9 \mathrm{~V}\right.$ vs $\mathrm{NHE}$ at $\mathrm{pH} 7$ [5] from water radiolysis [6-8] (through addition of the ${ }^{\bullet} \mathrm{OH}$ radical to the sulfur atom followed by elimination of either $\mathrm{OH}^{-}$or $\mathrm{H}_{2} \mathrm{O}$ ). The transients formed in the oxidation of Met-containing peptides and proteins by various one-electron oxidants have been well-characterized [9-15]. In the oxidation process, the initially formed sulfur radical cation can interact with electronrich atoms $(\mathrm{O}, \mathrm{N}$, or $\mathrm{S})$, yielding two-centered three-electron bonds. It can also irreversibly deprotonate, yielding a carbon-centered, $\alpha$-(alkylthio)alkyl radical $(\alpha S)$.

Despite many reports devoted to the detailed mechanisms of these radical reactions and transformations, some doubts remain as to their final fates (i.e., the stable oxidation products). Surprisingly, there are only a few reports that combine the complementary time-resolved and steady-state techniques in the photo- and radiation-induced oxidation of Met-containing peptides [3,4]. It is, therefore, rational to use a simple model compound, such as 3-MTPA or its acetylated analogue ( $N$-acetyl-3-(methylthio)propylamine, 3-AcMTPA) to carry out these complementary time-resolved (Pulse Radiolysis and/or Laser Flash Photolysis) and stationary (photochemical and/or $\gamma$-irradiation) experiments. 3-AcMTPA seems to be an even better 
model than 3-MTPA for peptides [16,17] (it contains a peptide-like bond due to the presence of the Ac group, see Figure 1), however, this is, to our knowledge, the first report on the oxidation of this model compound. 3-AcMTPA ( $N$-acetylated methionine without its carboxylic group) is interesting also because it simplifies the model structure eliminating a possibility of decarboxylation or a participation of the carboxylic group in sulfur radical cation stabilization.

In radiolytic and photolytic oxidation of aqueous solutions of Met and related peptides, the appearance of a broad absorption band centered at around 380-400 $\mathrm{nm}$ is taken as evidence for intramolecular $\left(>\mathrm{S} \therefore \mathrm{NH}_{2}\right)^{+}$bonding $[8,17,18]$. This assignment is also consistent with the identification of a similar transient absorption as $\left(>\mathrm{S} \therefore \mathrm{NH}_{2}\right)^{+}$in the one-electron oxidation of 3-(methylthio)propylamine (3-MTPA), a compound similar in structure to Met and 3AcMTPA (see Figure 1 for structures). In this work [17], the authors provided vibrational spectroscopic evidence (using the Time-Resolved Resonance Raman Spectroscopy) of intramolecular bonding in the oxidized 3-MTPA $\left(>\mathrm{S}^{\bullet+}\right)$ and showed that the observed, longlived $390 \mathrm{~nm}$ transient absorption of the radical is almost completely confined to the $\mathrm{S} \therefore \mathrm{N}$ bond.

In this work, we examined the time-resolved transient absorption evolution after the ${ }^{\bullet} \mathrm{OH}$ radical induced oxidation of 3-AcMTPA in aqueous solution. Moreover, the stable products from $\gamma$-irradiations of aqueous solutions of 3-AcMTPA were identified. Both time-resolved and steady-state experimental approaches allowed us, based on the model compound 3AcMTPA, to suggest the mechanism of one-electron oxidation which is critically important for unraveling the redox chemistry in sulfur-containing amino acids, peptides and proteins.

Figure 1 


\section{Experimental}

The synthetic procedure of $\mathrm{N}$-acetyl-3-(methylthio)propylamine was based on methionine decarboxylation [19] and the details of synthesis and its products characterization are given in the Supporting Data. The following instruments were used for spectral characterization of synthesized compounds: for NMR analysis was used Spectrometer Varian VNMR-S 400 $\mathrm{MHz}\left(400 \mathrm{MHz}{ }^{1} \mathrm{H}\right.$, and $100 \mathrm{MHz}{ }^{13} \mathrm{C}$, chemical shifts are reported in ppm units and in $\delta$ scale relative to TMS), data are reported as follows: chemical shift, multiplicity ( $\mathrm{s}=$ singlet, $\mathrm{t}$ =triplet, $\mathrm{q}=$ quartet, $\mathrm{m}=$ multiplet, $\mathrm{br}=$ broad), coupling constant, and integration. For both low- and high-resolution EI MS analysis was used Spectrometer AMD Intectra Mass AMD 402 and Spectrometer Bruker 320MS/450GC (mass values reported in $\mathrm{m} / \mathrm{z}$ units) and for IR analysis was used Spectrometer Bruker FT-IR IFS 66/s (KBr plates or film, vibration frequencies in $\mathrm{cm}^{-1}$, band abbreviation intensities: $\mathrm{s}=$ strong, $\mathrm{m}=$ middle, $\mathrm{w}=$ weak). Melting point was determined on Boetius apparatus.

$\gamma$-irradiations were carried out using a panoramic ${ }^{60} \mathrm{Co}$ source IL60PL Cis-Bio International (France) at the University Paris-Sud 11 (Orsay, France). The dose rate was determined by Fricke dosimetry $[20,21]$ to be $27.6 \mathrm{~Gy} \mathrm{~min}^{-1}$ for all of the samples. Samples ([3-AcMTPA] $=$ $1 \mathrm{mM})$ were purged by nitrous oxide $\left(\mathrm{N}_{2} \mathrm{O}\right)$ for approximately 30 minutes before $\gamma$ irradiations. Nitrous oxide was delivered by Alpha Gaz (France), and its purity was $99.998 \%$. Pulse radiolysis experiments were carried out on a Titan $8 \mathrm{MeV}$ Beta model TBS 8/16-1S linear accelerator located in the Radiation Laboratory at the University of Notre Dame (IN, USA). The pulse radiolysis experimental setup has been described in ref. [22]. In the current experiments, typical pulse lengths were 2.5 - 4 ns and the absorbed doses were between 5 and $10 \mathrm{~Gy}\left(1 \mathrm{~Gy}=1 \mathrm{~J} \mathrm{~kg}^{-1}\right)$. The optical path for the monitoring light beam was $1 \mathrm{~cm}$. 
Dosimetry was based on $\mathrm{N}_{2} \mathrm{O}$-saturated solutions of $10 \mathrm{mM} \mathrm{KSCN}$, taking a molar absorption coefficient of $7580 \mathrm{M}^{-1} \mathrm{~cm}^{-1}$ at $472 \mathrm{~nm}$ for the $(\mathrm{SCN})_{2}{ }^{--}$radical [23], taking a radiation chemical yield of $\mathrm{G}=0.635 \mu \mathrm{mol}$ per $1 \mathrm{~J}$ of absorbed energy in aqueous solutions The calculated effective ${ }^{\bullet} \mathrm{OH}$ radicals concentration was corrected according to the Schuler's formula [24], therefore, it is the concentration of $\mathrm{OH}$ radicals scavenged by the $0.1 \mathrm{mM}$ concentration of the scavenger used (3-AcMTPA), and the calculated (see Results and discussion section) rate constant of the reaction.

The mass spectra were recorded using a hybrid QTOF instrument (AB Sciex, model 5600+). Ions were generated by electrospray ionization (ESI) under the following conditions: a flow rate of $10 \mu \mathrm{L} / \mathrm{min}$, a dry gas flow of $8 \mathrm{~L} / \mathrm{min}$, a nebulizer pressure of 1.5 bar, a spray voltage of $5200 \mathrm{~V}$, and a drying gas temperature of $200 \mathrm{C}$. Analyst 1.6TF software (AB Sciex) was used to process the raw spectra. MS/MS fragmentation mass spectra were produced by collisions (CID - Collision-Induced Dissociation) with nitrogen gas in the Q2 section of the spectrometer.

\section{Results and discussion}

Pulse radiolysis. Figure 2 presents the transient absorption spectrum obtained at $4 \mu$ s delay time (with respect to the end of the electron pulse) in $\mathrm{N}_{2} \mathrm{O}$-saturated aqueous solution containing $0.1 \mathrm{mM}$ of 3-AcMTPA at $\mathrm{pH} 4.7$. The set of transient intermediates that were likely present were suggested based on the intermediates identified in the pulse radiolytic oxidation of methionine [6,7] and 3-MTPA [17]. The reference spectra of these transients have been reported in previous publications [9]. As it can be seen in Figure 3, the dominant and most stable species at longer delay times was the $\alpha$-(alkylthio)alkyl radicals (depicted as $\alpha S)$ produced with a similar kinetics to the decay of the intermolecular $(S . \cdot S)^{+}$dimer. This is in contrast to the previously reported studies on the radiolytic oxidation of 3- 
(methylthio)propylamine (3-MTPA, see Figure 1 for the structure), where the major intermediate was found to be an intramolecularly stabilized $\left(>\mathrm{S} \cdot \cdot \mathrm{NH}_{2}\right)^{+}$species [17]. Analysis of the pulse radiolysis data shows that 3 -AcMTPA reacts with ${ }^{\bullet} \mathrm{OH}$ with at a rate constant of $8 \times 10^{9} \mathrm{M}^{-1} \mathrm{~s}^{-1}$ (obtained from the plot of the pseudo-first order rate constants measured at various 3-AcMTPA concentrations $(0.1,0.2$ and $0.35 \mathrm{mM}))$, primarily by the addition of ${ }^{\bullet} \mathrm{OH}$ radicals at the sulfur site.

The sulfur-centered radical cation $>\mathrm{S}^{\bullet+}$ is formed as a result of a unimolecular $\mathrm{OH}^{-}$elimination or in a more complex reaction of proton-catalyzed elimination of water from the adduct $\left(3-\mathrm{AcMTPA}-\mathrm{OH}^{\bullet}+\mathrm{H}^{+} \rightarrow 3\right.$-AcMTPA $\left.{ }^{+}+\mathrm{H}_{2} \mathrm{O}\right)$ [25]. The observed decay rate constant of this process was calculated from the $>\mathrm{S} \therefore \mathrm{OH}$ concentration profile in Fig. 3 to be $7 \times 10^{5} \mathrm{~s}^{-1}$.

Analysis of transient absorption spectra obtained in pulse radiolysis experiments with optical detection can be difficult due to the overlap of multiple transient absorptions with similar features. For this reason, spectra were resolved into individual components by a linear regression method which employs the absorption additive law, and known reference spectra of possible transients. The method is based on the following equation:

$$
\Delta A\left(\lambda_{j}\right)=\sum_{i=1}^{n} \epsilon_{i}\left(\lambda_{j}\right) a_{i}
$$

where $\Delta \mathrm{A}\left(\lambda_{\mathrm{j}}\right)$ is the sum of the absorbances of all species at $\lambda_{\mathrm{j}}, \varepsilon_{\mathrm{i}}\left(\lambda_{\mathrm{j}}\right)$ is the molar absorption coefficient of the $i^{\text {th }}$ species at the $j^{\text {th }}$ wavelength of observation, and $a_{i}$ is equal to the concentration $c_{i}$ multiplied by the optical path length. This method has been described elsewhere $[9,26]$. Here, the transients considered were $2 \mathrm{c}-3 \mathrm{e}$ bonded radical species coming from 3-AcMTPA: intramolecular $(\mathrm{S} \therefore \mathrm{N})^{+}$and intermolecular $(\mathrm{S} \therefore \mathrm{S})^{+}$. It is generally assumed 
that their absorption spectra are similar to those of other sulfur containing compounds [27]. The other species considered are: intramolecular three-electron bonded $(\mathrm{S} \therefore \mathrm{O})^{+}$, OH radical adduct to the sulfur moiety $>\mathrm{S} \therefore \mathrm{OH}$ (see ref [28] for a detailed discussion of this species' structure), and a carbon-centered $\alpha$-(alkylthio)alkyl radical $(\alpha S)$. A deconvolution procedure to fit the experimental spectra presented in Fig. 2 and to calculate the radiation chemical yields ( $\mathrm{G}$ values) of individual intermediates in Fig. 3 was performed using the following reference data: for $\alpha \mathrm{S} \varepsilon_{290}=3000( \pm 600) \mathrm{M}^{-1} \mathrm{~cm}^{-1}$, for $(>\mathrm{S} \therefore \mathrm{NH}-)^{+} \varepsilon_{390}=4520 \mathrm{M}^{-1} \mathrm{~cm}^{-1}$, for $(\mathrm{S} \cdot \cdot \mathrm{S})^{+} \varepsilon_{480}=6880 \mathrm{M}^{-1} \mathrm{~cm}^{-1}$, for $>\mathrm{S} \therefore \mathrm{OH} \varepsilon_{340}=3400 \mathrm{M}^{-1} \mathrm{~cm}^{-1}[26]$.

The sum in equation 1 represents a total absorbance ( $\Delta \mathrm{OD})$ of all species present. For any particular time delay of the experiment, the analysis included the same equation for each $\lambda_{\mathrm{i}}$. The results of this procedure were then applied to calculate the concentration profiles for each individual component vs. time delay with respect to the end of electron pulse.

Figure 2

As can be seen in the Figure 2 , the use of 4 input components $\left(\alpha \mathrm{S},(>\mathrm{S} \therefore \mathrm{NH}-)^{+}, \mathrm{S} \therefore \mathrm{S}^{+}\right.$and $>\mathrm{S} \therefore \mathrm{OH})$ gives an excellent fit to the experimental data. Knowing the mechanism for similar systems from previous studies, [8,29-31] the use of $\alpha \mathrm{S}, \mathrm{S} \therefore \mathrm{S}^{+}$and $>\mathrm{S} \therefore \mathrm{OH}$, reference absorption spectra is quite obvious, however, one can ask if it is necessary to use an additional $(>\mathrm{S} \therefore \mathrm{NH}-)^{+}$component to resolve the spectra (since the electron density on the acetylated amino group is certainly much lower compared to that of $-\mathrm{NH}_{2}$ ). The calculations have shown it is absolutely necessary to use a component absorbing in the $350-400 \mathrm{~nm}$ range (without this input, the fit was really very poor). Since there are no oxygen atoms from the carboxylic group present for the investigated compound, this "additional" component could be logically assigned to the $(>\mathrm{S} \therefore \mathrm{NH}-)^{+}$intermediate formed between the oxidized sulfur radical cation 
and a "peptide-bond" nitrogen. Moreover, its relatively fast decay (as compared to the longlived (>S $\therefore \mathrm{NH}-)^{+}$observed for 3-MTPA [17]), has already been reported by Ignasiak et al [4] where the fast decay of this species was rationalized by a weaker stabilization of the sulfurcentered radical cation by the "peptide-bond nitrogen" relative to stabilization by an amino group. This weaker stabilization is due to the delocalized electron density of the lone pair on the nitrogen in a peptide bond relative to that in an amino group. The lone electron pairs are necessary to form the three-electron sulfur-nitrogen bonds under consideration. Such threeelectron bonding can also be achieved with the participation of the carbonyl oxygen atom $[16,31,32]$, however, this would require the formation of a thermodynamically and kinetically [33] less favorable seven-membered ring compared to a five-membered ring with the nitrogen atom. On the other hand, it has been recently reported [32] that such $(\mathrm{S} \therefore \mathrm{O})^{+}$formation gains the energy benefit of $0.04 \mathrm{eV}$ in cyclic Met-Met dipeptides. In view of these literature inconsistencies and due to similarly shaped optical spectra of $(\mathrm{S} \therefore \mathrm{O})^{+}$and $(>\mathrm{S} \therefore \mathrm{NH}-)^{+}$both stabilization alternatives are presented in Scheme 1. However, based on experimental results reported by Yashiro for N-Ac-Methione [34] (the compound similar in structure to 3AcMTPA) where only the presence of $(>\mathrm{S} \therefore \mathrm{NH}-)^{+}$was detected, the $(>\mathrm{S} \therefore \mathrm{NH}-)^{+}$formation seems to be more likely than the $(\mathrm{S} \therefore \mathrm{O})^{+}$.

When the intramolecular stabilization becomes inefficient, the intermolecularly stabilized $\mathrm{S} \therefore \mathrm{S}^{+}$species becomes dominant and can be observed even tens of microseconds after the electron pulse. At longer delay times (> $100 \mu \mathrm{s}$ ) the only species left was the $\alpha \mathrm{S}$ radical with its characteristic, sharp absorption band at ca. $290 \mathrm{~nm}$. This relatively stable, carbon-centered radical should, therefore, be a precursor for both observed stable products (see discussion below).

Figure 3 
The spectral observations presented above for the early events after one-electron oxidation of 3-AcMTPA differ from those for 3-MTPA [17]. In contrast to the oxidation of 3-MTPA, we do not observe the long-lived transient absorption signal at $390 \mathrm{~nm}$. Instead, the long-lived transient observed for the $\mathrm{N}$-acetylated analogue showed an absorption band at around 290$300 \mathrm{~nm}$. Based on previous results, this signal is assigned to the carbon-centered $\alpha-$ (alkylthio)alkyl radical $(\alpha \mathrm{S})$. The absorption signal at $390 \mathrm{~nm}$ (similar to that for 3-MTPA $\left.\left(>\mathrm{S} \therefore \mathrm{NH}_{2}\right)^{+}\right)$was also observed shortly after the electron pulse, but this signal decayed rapidly on the microsecond timescale as can be seen in Figure 3. The short lifetime of the $(>\mathrm{S} \therefore \mathrm{NH}-\mathrm{Ac})^{+}$indicates its low stability, likely due to the relatively (i.e. as compared to interactions with the amino group that occurs for 3-MTPA) low electron density on the $\mathrm{N}$ atom and consequently a weaker stabilization of this transient compared to that from $\left(>\mathrm{S} \therefore \mathrm{NH}_{2}\right)^{+}$formed from 3-MTPA.

The total radiation chemical yield of all species can be calculated by adding the yields of all transients presented in Figure 3. By doing so one can realize that the maximum value of $G$ equals $0.43 \mu \mathrm{mol} / \mathrm{J}$ while the radiation chemical yield of $\mathrm{OH}$ radicals scavenged by $0.1 \mathrm{mM} 3$ AcMTPA should be $0.549 \mu \mathrm{mol} / \mathrm{J}$. The obtained value only accounts for ca. $80 \%$ of the expected concentration. This deficit in materials balance can be a consequence of an unknown "real" value of the $\alpha \mathrm{S}$ extinction coefficient. For technical reasons the value of $\varepsilon_{290}=3000( \pm$ 600) $\mathrm{M}^{-1} \mathrm{~cm}^{-1}$ was taken from ref. [26,35] where it was measured for Methionine and not for its decarboxylated analogue 3-AcMTPA studied here. The "real" value of $\varepsilon$ can be different due to the absence of the carboxylic group. On the other hand, we cannot exclude the possibility that 3-AcMTPA oxidation yields other radicals, not detected in the optical absorption region of our experiment $(270-700 \mathrm{~nm})$. 
Mass spectrometry. The transients formed in the oxidation of Met-containing peptides by $\mathrm{OH}$ radicals are well characterized $[6,26,36,37]$, whereas their reaction paths leading to stable products still remain unclear. One of the most frequent modifications in peptides containing a thioether group is its conversion into the sulfoxide form (e.g. MetS=O). Interestingly, such a two-electron oxidation product, $\mathrm{MetS}=\mathrm{O}$, has been observed also in $\mathrm{OH}$-radical oxidation carried out in anaerobic conditions [3]. It is therefore desirable to characterize the major stable modifications of 3-AcMTPA (as a peptide model) under anaerobic oxidation conditions $\left(\mathrm{N}_{2} \mathrm{O}-\right.$ saturated aqueous solutions).

The samples of 3-AcMTPA were irradiated in a $\gamma$-source as described in the Experimental section ( $1 \mathrm{mM}, \mathrm{N}_{2} \mathrm{O}$-saturated aqueous solutions, $\left.\mathrm{pH}=4.7\right)$. The mass spectrum presented in Figure 4 (high resolution masses are listed in Table 1) reveals the presence of unreacted substrate $\left(\mathrm{MH}^{+} \mathrm{m} / \mathrm{z}\right.$ 148, $\mathrm{MNa}^{+} \mathrm{m} / \mathrm{z}$ 170) as well as some additional peaks, not observed for non-irradiated samples. The most intense new peaks that appeared after gamma-irradiation (27.6 Gy/min, irradiated for $22 \mathrm{~min} ., 607 \mathrm{~Gy}$ absorbed dose) of the sample are: $\mathrm{m} / \mathrm{z} 164,180$, 186 and 293 (the exact, monoisotopic masses of the major stable products are collected in Table 1). The exact mass peak with $\mathrm{m} / \mathrm{z} 164$ corresponds to the addition of one oxygen atom to the substrate. Its fragmentation (TOF-MSMS spectrum presented in the Supplementary Data section) suggests that the oxygen atom adds to the sulfur moiety, therefore the peak is interpreted as a sulfoxide product $\left(>\mathrm{S}=\mathrm{OH}^{+}\right)$. The peak with $\mathrm{m} / \mathrm{z} 186$ is suggested to be the sulfoxide product with a proton substituted by a sodium cation $\left(>\mathrm{S}=\mathrm{ONa}^{+}\right)$. The peak with $\mathrm{m} / \mathrm{z} 180$ corresponds most likely to the sulfone product $\left(>\mathrm{S}(=\mathrm{O})_{2} \mathrm{H}^{+}\right)$, doubly oxidized 3AcMTPA), formed in the simple chemical reaction of the substrate or the sulfoxide with $\mathrm{H}_{2} \mathrm{O}_{2}$ generated in the water radiolysis process. The exact mass of a peak with $\mathrm{m} / \mathrm{z} 293.1367$ suggests that this peak could be formed from two $\alpha$-(alkylthio)alkyl radicals $(\alpha S)$. Therefore, it can be interpreted as a dimer formed as the result of the combination of two $\alpha \mathrm{S}$ radicals 
(exact mass error is only $5 \mathrm{ppm}$ ). The exact mass measurements as well as the isotopic patterns (not shown) confirm the expected elemental composition of the two major stable products (the sulfoxide and the dimer) suggested above.

Figure 4

Assuming that the peak at $\mathrm{m} / \mathrm{z}=293$ is indeed the suggested $\alpha \mathrm{S}$ dimerization (radical combination) product, more than one isomer of such $\alpha \mathrm{S}$ radicals should be considered: $-\mathrm{CH}_{2}-\mathrm{S}-\mathrm{C}^{\bullet} \mathrm{H}_{2}$ (R1) and $-\mathrm{C}^{\bullet} \mathrm{H}-\mathrm{S}-\mathrm{CH}_{3}(\mathrm{R} 2)$. Combination of such radicals should lead to the formation of three isomeric dimers: R1-R1, R2-R2 and R1-R2 dimers, all having the same $\mathrm{m} / \mathrm{z}$ but most likely somewhat different fragmentation pattern. The LC-MS chromatogram presented in Figure 5, however, shows just one dominant peak for the $\mathrm{m} / \mathrm{z} 293$. The fragmentation spectrum acquired for this $\mathrm{m} / \mathrm{z} 293$ peak yields two intense peaks with $\mathrm{m} / \mathrm{z}$ values of 245 and 197 (see Table 1 for the exact masses). This fragmentation is characteristic of the loss of one or two $-\mathrm{S}-\mathrm{CH}_{3}$ groups together with the formation of a double bond (see Supplementary Data for more details of the MS fragmentation spectra). Such a fragmentation pattern is possible exclusively for a dimeric product (m/z 293) formed from two R2 radicals. This leads to the conclusion that the $\alpha \mathrm{S}$ radical observed spectroscopically in the pulse radiolysis experiments is a radical centered on a $\gamma-\mathrm{CH}-$ carbon atom (and not the terminal one). It should not be surprising because such a $\gamma$-carbon centered radical is more stable than the terminal $\delta$-carbon radical [38]:

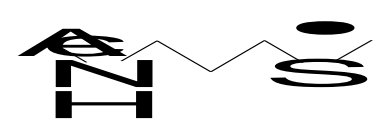

$\gamma$-carbon radical

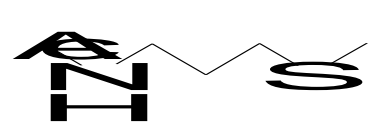

$\delta$-carbon radical 
The "dimeric" stable product formation mechanism is somewhat similar to the mechanism of photocyclization of the methionine-benzophenone dyads studied by Lewandowska et al [39]. In that communication, the authors reported that the proton was donated mainly by the terminal $\delta-\mathrm{CH}_{3}$ group rather than by the $\gamma-\mathrm{CH}_{2}$ group. This is in contrast with our observations, where the $\alpha \mathrm{S}$ radical is suggested (based on the mass spectrometry fragmentation experiments) to be localized on the $\gamma-\mathrm{CH}-$ carbon. However, in the case of intramolecular quenching (as discussed by Lewandowska et al), the geometrical restrictions may cause a better accessibility of the exposed, terminal $\delta-\mathrm{C}^{\bullet} \mathrm{H}_{2}$ radical to produce the observed $\mathrm{C}-\mathrm{C}$ coupling.

The absence of such steric restrictions, as is the case for intermolecular reactions, together with the higher thermodynamical stability of $\gamma$-type radicals $\left(-\mathrm{C}^{\bullet} \mathrm{H}-\mathrm{S}-\mathrm{CH}_{3}\right.$ rather than $-\mathrm{CH}_{2}-$ $\mathrm{S}-\mathrm{C}^{\bullet} \mathrm{H}_{2}$ ) rationalizes our experimental observation of one, dominant stable product of $\mathrm{m} / \mathrm{z}$ 293 and not a mixture of isomers (see chromatogram in Fig. 5).

Table 1

This has implications for the interpretations of the pulse radiolysis data, proving that although both $\alpha \mathrm{S}$ radicals can be formed (as a result of $>S^{\bullet+}$ radical cation deprotonation) mostly the more stable one, centered on the $\gamma-\mathrm{CH}-$ carbon, contributes to the formation of stable products. The analogue mechanism can possibly be generalized for the oxidation of Metcontaining peptides and proteins.

Another stable product detected in large amounts after gamma-irradiations of $\mathrm{N}_{2} \mathrm{O}$-saturated 3-AcMTPA samples exhibits $\mathrm{m} / \mathrm{z}=164.0752$ with a clear peak in the LC-MS chromatogram (Fig. 5). The difference of 16 (exact mass of 15.9949) from the parent compound suggests the 
addition of oxygen to it. Fragmentation MSMS experiments (i.e. elimination of the $-\mathrm{S}(=\mathrm{O})-$ $\mathrm{CH}_{3}$ group) together with our previously published results [3] suggest that this product is a 3AcMTPA sulfoxide formed in oxygen-free aqueous solutions as a result of the disproportionation reaction of $\alpha \mathrm{S}$ radicals followed by reaction with water (besides a more "trivial" and well-known mechanism in which 3-AcMTPA reacts with hydrogen peroxide from water radiolysis). The mechanism of sulfoxide formation is shown in the Supplementary Data section (Fig. S4) and described in more detail in ref. [3]. In this report, however, the experiments with catalase (the enzyme that removes the peroxide) were not performed therefore the conclusion on $\alpha \mathrm{S}$ disproportionation mechanism is based on our previously reported results on Met-containing peptides [3].

Figure 5

Scheme 1

\section{Conclusions}

The mechanism of ${ }^{\bullet} \mathrm{OH}$ radical induced oxidation of 3-AcMTPA has the same primary steps (with an obvious exclusion of a decarboxylation reaction) as in the case of Met and Metcontaining peptides as shown by pulse radiolysis as summarized in Scheme 1. The initially formed three-electron bonded intermediates (intermolecular $(>\mathrm{S} \therefore \mathrm{S}<)^{+}$and intramolecular $(>\mathrm{S} \therefore \mathrm{NH}-\mathrm{Ac})^{+}$and/or $\left.(>\mathrm{S} \therefore \mathrm{O})^{+}\right)$eventually lead to the formation of relatively stable (its lifetime can be estimated based on the pulse radiolysis data to be on the millisecond time 
scale), carbon-centered, $\alpha$-(alkylthio)alkyl radical $(\alpha \mathrm{S})$ produced from the deprotonation of the $\mathrm{S}$-centered radical cation $\left(>\mathrm{S}^{\bullet+}\right)$.

It was shown that the $\alpha \mathrm{S}$ radical is centered mainly on the $\gamma-\mathrm{CH}-$ carbon (and not on the terminal carbon atom of the Met side chain), and these radicals contribute to the formation of stable products ( $\alpha \mathrm{S}$ dimer) as confirmed by MS and MSMS experiments. All the major stable products (namely the $\alpha \mathrm{S}$ dimer and the sulfoxide), as detected by mass spectrometry techniques, were most likely formed with the participation of the same precursor, the $\alpha \mathrm{S}$ radical.

Similar reaction mechanisms could take place in real biological conditions and for a variety of sulfur-containing amino acids and peptides that exist in nature.

\section{Acknowledgments}

PF acknowledges the National Science Centre, Poland for financial support of this work within grant no. UMO-2013/11/B/ST4/00811. TP and PF gratefully acknowledge the Notre Dame Radiation Laboratory staff and personally Professor Ian Carmichael for his hospitality during the authors' stay at Notre Dame Radiation Laboratory. The assistance of Professor Chantal Houée-Levin from the University of Paris-Sud (Orsay, France) in gamma-irradiations is greatly appreciated. TP and PF thank the CLIO team (Orsay, France) for technical assistance and the financial support within grant no. CLIO IC 15-001. We would like to thank Prof. Krzysztof Bobrowski (IChTJ, Warsaw, Poland for his help in radiation chemistry data interpretation and corrections of the manuscript. We are grateful to Dr.

Gordon L. Hug for fruitful discussions and assistance in the pulse radiolysis measurements that were obtained using the Radiation Laboratory Linac which is supported by the US Department of Energy of Science, Office of Basic Energy Science under Award Number DE-FC02-04ER15533. This is document number NDRL-5137 from the Notre Dame Radiation Laboratory. 


\section{References}

[1] Davies MJ. Oxidative Damage to Proteins. Encyclopedia of Radicals in Chemistry, Biology and Materials: John Wiley \& Sons, Ltd; 2012.

[2] Davies MJ. The oxidative environment and protein damage. Biochimica et Biophysica Acta (BBA) - Proteins and Proteomics 2005;1703(2):93-109.

[3] Ignasiak M, Scuderi D, de Oliveira P, Pedzinski T, Rayah Y, Levin CH. Characterization by mass spectrometry and IRMPD spectroscopy of the sulfoxide group in oxidized methionine and related compounds. Chemical Physics Letters 2011;502(1-3):29-36.

[4] Ignasiak MT, Pedzinski T, Rusconi F, Filipiak P, Bobrowski K, Houée-Levin C, Marciniak B. Photosensitized Oxidation of Methionine-Containing Dipeptides. From the Transients to the Final Products. Journal of Physical Chemistry B 2014;118(29):8549-8558.

[5] Wardman P. Reduction Potentials of One-Electron Couples Involving Free Radicals in Aqueous Solution. Journal of Physical and Chemical Reference Data 1989;18(4):1637-1755.

[6] Bobrowski K, Holcman J. Formation of 3-Electron Bonds in One-Electron Oxidized Methionine Dipeptides - A Pulse Radiolytic Study. International Journal of Radiation Biology 1987;52(1):139-144.

[7] Hiller KO, Masloch B, Goebl M, Asmus KD. Mechanism of the hydroxyl radical induced oxidation of methionine in aqueous solution. Journal of the American Chemical Society 1981;103(10):2734-2743.

[8] Asmus KD, Gobl M, Hiller KO, Mahling S, Monig J. S-N and S-O 3-Electron-Bonded Radicals and Radical Cations in Aqueous-Solutions. Journal of the Chemical Society-Perkin Transactions 2 1985(5):641-646.

[9] Bobrowski K, Hug GL, Pogocki D, Marciniak B, Schöneich C. Stabilization of sulfide radical cations through complexation with the peptide bond: Mechanisms relevant to oxidation of proteins containing multiple methionine residues. Journal of Physical Chemistry B 2007;111(32):9608-9620. 
[10] Bobrowski K, Marciniak B, Hug GL. 4-Carboxybenzophenone-Sensitized Photooxidation of Sulfur-Containing Amino-Acids - Nanosecond Laser Flash-Photolysis and Pulse-Radiolysis Studies. Journal of the American Chemical Society 1992;114(26):10279-10288.

[11] Pedzinski T, Markiewicz A, Marciniak B. Photosensitized oxidation of methionine derivatives. Laser flash photolysis studies. Research on Chemical Intermediates 2009;35(4):497-506.

[12] Pedzinski T, Bobrowski K, Ignasiak M, Kciuk G, Hug GL, Lewandowska-Andralojc A, Marciniak B. 3-Carboxybenzophenone (3-CB) as an efficient sensitizer in the photooxidation of methionyl-leucine in aqueous solutions: Spectral, kinetic and acid-base properties of 3-CB derived transients. Journal of Photochemistry and Photobiology a-Chemistry 2014;287:1-7.

[13] Bobrowski K, Houée-Levin C, Marciniak B. Stabilization and Reactions of Sulfur Radical Cations: Relevance to One-Electron Oxidation of Methionine in Peptides and Proteins. CHIMIA International Journal for Chemistry 2008;62(9):728-734.

[14] Bobrowski K, Hug GL, Pogocki D, Marciniak B, Schöneich C. Sulfur Radical Cation-Peptide Bond Complex in the One-Electron Oxidation of S-Methylglutathione. Journal of the American Chemical Society 2007;129(29):9236-9245.

[15] Goez M, Rozwadowski J, Marciniak B. CIDNP Spectroscopic Observation of (S:.+N) Radical Cations with a Two-Center Three-Electron Bond During the Photooxidation of Methionine. Angewandte Chemie International Edition 1998;37(5):628-630.

[16] Morozova OB, Korchak SE, Sagdeev RZ, Yurkovskaya AV. Time-Resolved Chemically Induced Dynamic Nuclear Polarization Studies of Structure and Reactivity of Methionine Radical Cations in Aqueous Solution as a Function of pH. The Journal of Physical Chemistry A 2005;109(45):10459-10466.

[17] Tripathi GNR, Tobien T. The intramolecular sulfur-nitrogen bond in aqueous 3(methylthio)propylamine radical cation. Journal of Physical Chemistry A 2001;105(14):34983504.

[18] Hug GL, Marciniak B, Bobrowski K. Acid-base equilibria involved in secondary reactions following the 4-carboxybenzophenone sensitized photooxidation of methionylglycine in 
aqueous solution. Spectral and time resolution of the decaying $(\mathrm{S}-\mathrm{N})(+)$ radical cation. Journal of Physical Chemistry 1996;100(36):14914-14921.

[19] Hashimoto M, Eda Y, Osanai Y, Iwai T, Aoki S. A novel decarboxylation of ALPHA-amino acids. A facile method of decarboxylation by the use of 2-cyclohexen-1-one as a catalyst. Chemistry Letters 1986(6):893-896.

[20] Matthews RW. Aqueous chemical dosimetry. The International Journal of Applied Radiation and Isotopes 1982;33(11):1159-1170.

[21] Jayson GG, Parsons BJ, Swallow AJ. Some Simple, Highly Reactive, Inorganic Chlorine Derivatives in Aqueous-Solution - Their Formation Using Pulses of Radiation and Their Role in Mechanism of Fricke Dosimeter. Journal of the Chemical Society-Faraday Transactions I 1973(9):1597-1607.

[22] Hug GL, Wang Y, Schöneich C, Jiang PY, Fessenden RW. Multiple time scales in pulse radiolysis. Application to bromide solutions and dipeptides. Radiation Physics and Chemistry 1999;54(6):559-566.

[23] Janata E, Schuler RH. Rate-Constant for Scavenging Eaq- in N2O-Saturated Solutions. Journal of Physical Chemistry 1982;86(11):2078-2084.

[24] Schuler RH, Hartzell AL, Behar B. Track Effects in Radiation Chemistry. Concentration Dependence for the Scavenging of $\mathrm{OH}$ by Ferrocyanide in $\mathrm{N}_{2} \mathrm{O}$-Saturated Solutions. Journal of Physical Chemistry 1981;85:192-199.

[25] Wisniowski PB, Hug GL, Pogocki D, Bobrowski K. Efficient $\alpha$-(Alkylthio)alkyl-Type Radical Formation in $\cdot \mathrm{OH}$-Induced Oxidation of $\alpha$-(Methylthio)acetamide. The Journal of Physical Chemistry A 2010;114(1):105-116.

[26] Schöneich C, Pogocki D, Bobrowski K, Hug GL. Free Radical Reactions of Methionine in Peptides: Mechanisms Relevant to $\beta$-Amyloid Oxidation and Alzheimer's Disease. Journal of the American Chemical Society 2003;125(45):13700-13713.

[27] Marciniak B, Hug GL, Kozubek H, Bobrowski K. Mechanism of 4-carboxybenzophenonesensitized photooxidation of methionine-containing dipeptides and tripeptides in aqueous solution. Journal of Physical Chemistry 1995;99(36):13560-13568. 
[28] Janik I, Tripathi GNR. The early events in the OH radical oxidation of dimethyl sulfide in water. The Journal of Chemical Physics 2013;138(4):044506.

[29] Asmus KD. Stabilization of oxidized sulfur centers in organic sulfides. Radical cations and odd-electron sulfur-sulfur bonds. Accounts of Chemical Research 1979;12(12):436-442.

[30] Bobrowski K. Free radicals in chemistry, biology and medicine: contribution of radiation chemistry. Nukleonika 2005;50:S67-S76.

[31] Filipiak P, Hug GL, Bobrowski K, Pedzinski T, Kozubek H, Marciniak B. Sensitized Photooxidation of S-Methylglutathione in Aqueous Solution: Intramolecular (S therefore O) and (S therefore N) Bonded Species. Journal of Physical Chemistry B 2013;117(8):23592368 .

[32] Köchling T, Morozova OB, Yurkovskaya AV, Vieth H-M. Magnetic Resonance Characterization of One-Electron Oxidized Cyclic Dipeptides with Thioether Groups. The Journal of Physical Chemistry B 2016;120(35):9277-9286.

[33] Bobrowski K, Hug GL, Marciniak B, Miller B, Schöneich C. Mechanism of One-Electron Oxidation of $\beta$-, $\gamma$-, and $\delta$-Hydroxyalkyl Sulfides. Catalysis through Intramolecular Proton Transfer and Sulfur-Oxygen Bond Formation. Journal of the American Chemical Society 1997;119(34):8000-8011.

[34] Yashiro H, White RC, Yurkovskaya AV, Forbes MDE. Methionine Radical Cation: Structural Studies as a Function of $\mathrm{pH}$ Using $\mathrm{X}$ - and Q-Band Time-Resolved Electron Paramagnetic Resonance Spectroscopy. The Journal of Physical Chemistry A 2005;109(26):5855-5864.

[35] Hiller KO, Asmus KD. Tl2+ and Ag2+ Metal-ion-induced Oxidation of Methionine in Aqueous Solution. A Pulse Radiolysis Study. International Journal of Radiation Biology and Related Studies in Physics, Chemistry and Medicine 1981;40(6):597-604.

[36] Miller BL, Kuczera K, Schöneich C. One-Electron Photooxidation of N-Methionyl Peptides. Mechanism of Sulfoxide and Azasulfonium Diastereomer Formation through Reaction of Sulfide Radical Cation Complexes with Oxygen or Superoxide. Journal of the American Chemical Society 1998;120(14):3345-3356. 
[37] Nauser T, Schöneich C. Thiyl radicals abstract hydrogen atoms from the C-alpha-H bonds in model peptides: Absolute rate constants and effect of amino acid structure. Journal of the American Chemical Society 2003;125(8):2042-2043.

[38] Coote ML, Lin CY, Zipse H. The Stability of Carbon-Centered Radicals. Carbon-Centered Free Radicals and Radical Cations: John Wiley \& Sons, Inc.; 2010. p 83-104.

[39] Lewandowska-Andralojc A, Kazmierczak F, Hug GL, Hörner G, Marciniak B. Photoinduced CC-coupling Reactions of Rigid Diastereomeric Benzophenone-Methionine Dyads. Photochemistry and Photobiology 2013;89(1):14-23. 
Figure captions:

Figure 1. Structures of methionine, 3-(methylthio)propylamine and $N$-acetyl-3(methylthio)propylamine.

Figure 2. Example of spectral resolution of an irradiated aqueous solution of 3-AcMTPA (4 $\mu$ s after the electron pulse), $\mathrm{N}_{2} \mathrm{O}$ saturated, $\mathrm{pH}=4$.7. The symbols represent: ( $\left.\square\right) \alpha \mathrm{S}$ individual

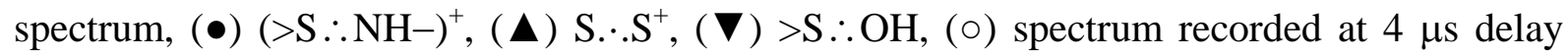
time, (-) sum of all individual components of the acquired spectrum (according to the Lambert-Beer absorbance additivity principle).

Figure 3. Concentration profiles calculated at different delay times in respect to the electron pulse. Details of dosimetry calculations are given in the Experimental section. Effective $\mathrm{OH}-$ radicals concentration (scavenged by $[3-A c M T P A]=0.1 \mathrm{mM}$ ) calculated based on KSCN dosimetry. The symbols represent: $(\boldsymbol{\square}) \alpha \mathrm{S},(\bullet)(>\mathrm{S} \therefore \mathrm{NH}-)^{+},(\boldsymbol{\Delta}) \mathrm{S} \cdot . \mathrm{S}^{+},(\boldsymbol{\nabla})>\mathrm{S} \therefore \mathrm{OH}$.

Figure 4. TOF-MS spectrum of a 3-AcMTPA aqueous solution (1 mM, pH=4.7) after gamma irradiation (flow injection method: $\mathrm{MH}^{+} 148.1,>\mathrm{S}=\mathrm{OH}^{+} 164.1, \mathrm{MNa}^{+} 170.1,>\mathrm{S}(=\mathrm{O}){ }_{2} \mathrm{H}^{+} 180.1$, $\mathrm{MK}^{+}$186.1, dimerH ${ }^{+}$293.2).

Figure 5. LC-MS chromatogram of irradiated aqueous solution of 3-AcMTPA (1 mM solution, $\mathrm{N}_{2} \mathrm{O}$-saturated, $\mathrm{pH}=4.7$, irradiated in a $\gamma$-source as described in the Experimental section).

Scheme 1. Mechanism of $\alpha \mathrm{S}$ radical and stable products formation in $\mathrm{OH}$-radical induced oxidation of 3-AcMTPA. 
Figure 1

$\mathrm{CH}_{3}-\mathrm{S}-\left(\mathrm{CH}_{2}\right)_{2}-\underset{\mid}{\mathrm{COOH}}$

methionine

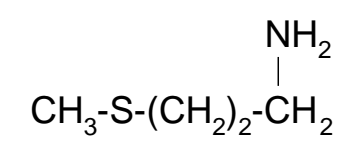

3-(methylthio)propylamine

(3-MTPA)

$$
\mathrm{CH}_{3}-\mathrm{S}-\left(\mathrm{CH}_{2}\right)_{2}-\stackrel{\mathrm{I}}{\mathrm{CH}}-(\mathrm{C}=\mathrm{O}) \mathrm{CH}_{3}
$$

$\mathrm{N}$-acetyl-3-(methylthio)propylamine

(3-AcMTPA) 
Figure 2

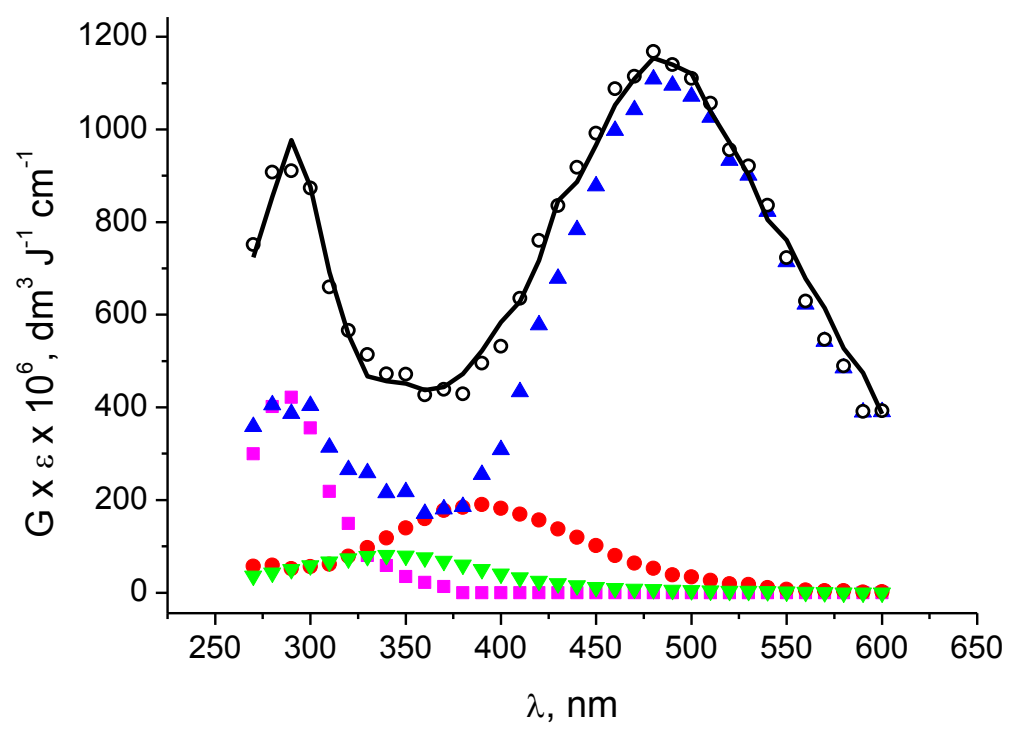


Figure 3

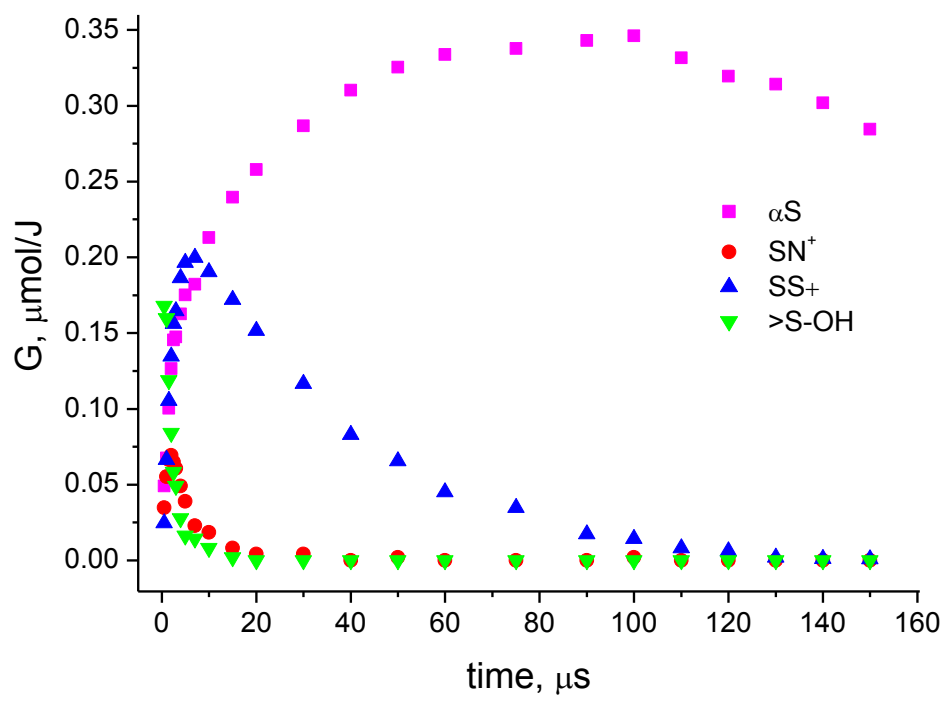


Figure 4

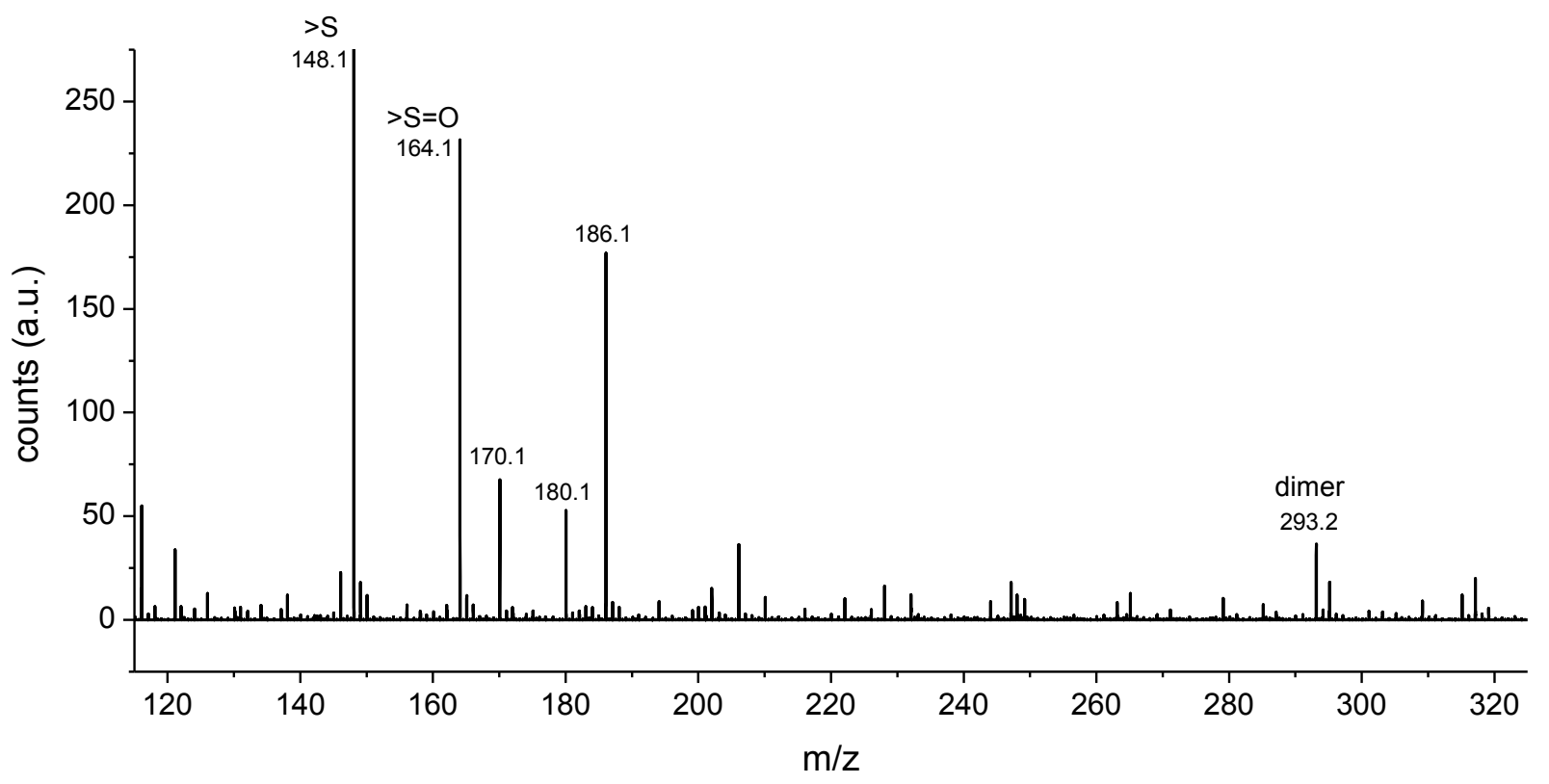


Figure 5

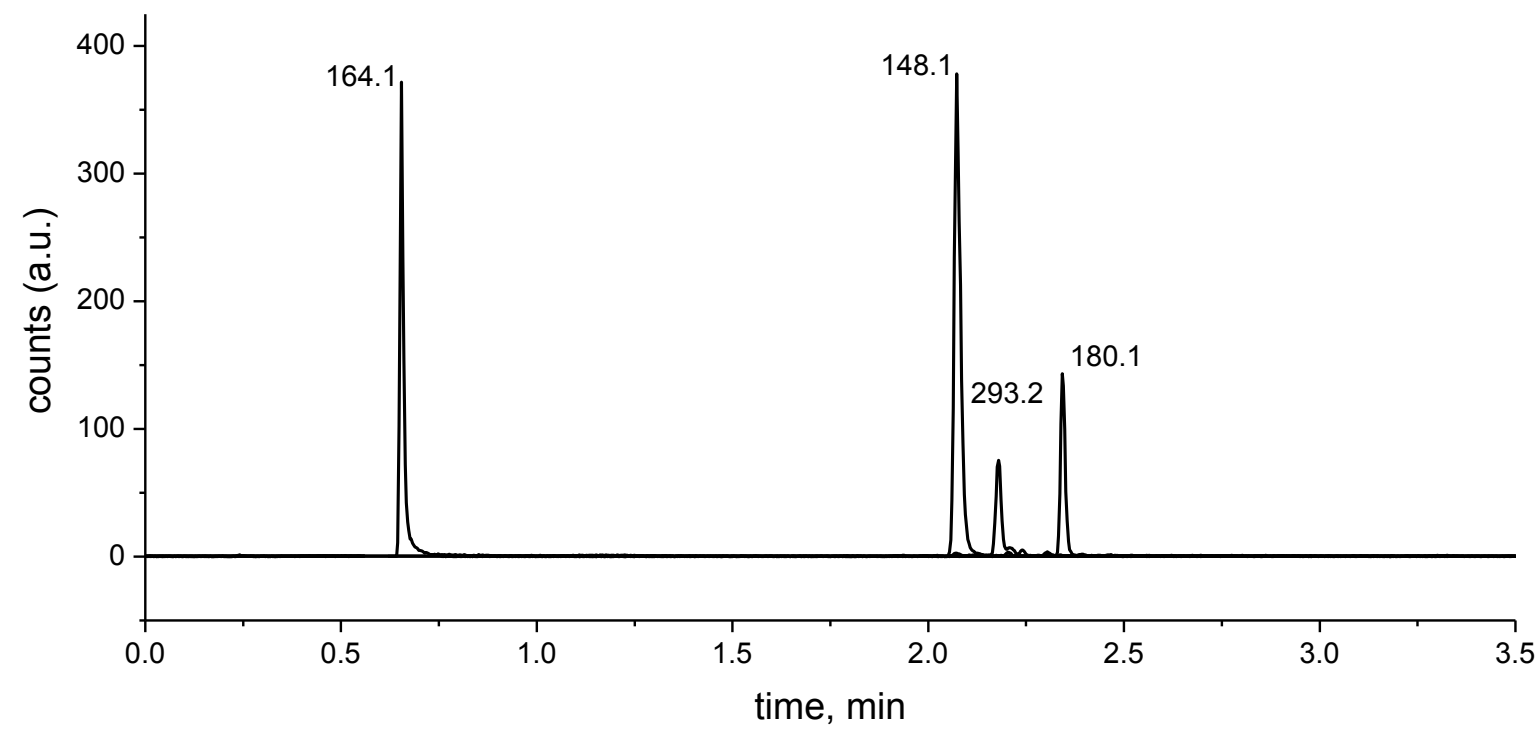


Scheme 1

$$
\text { (c) }
$$


Table 1

\begin{tabular}{|c|c|c|c|}
\hline & $\begin{array}{c}\mathbf{M H}^{+} \text {exact mass } \\
\text { (theoretical) }\end{array}$ & MH $^{+}$observed & $\begin{array}{c}\text { CID }^{*} \text { fragments } \\
\text { (most abundant) }\end{array}$ \\
\hline$>\mathbf{S}$ & 148.0796 & 148.0804 & 100.0763 \\
\hline$>\mathbf{S}=\mathbf{O}$ & 164.0745 & 164.0752 & 100.0765 \\
\hline dimer & 293.1352 & 293.1367 & $245.1322,197.1289$ \\
\hline
\end{tabular}

* CID - Collision-Induced Dissociation 


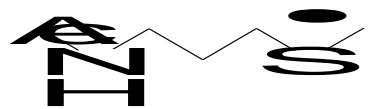

$\gamma$-carbon radical

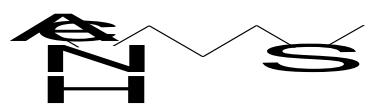

$\delta$-carbon radical 


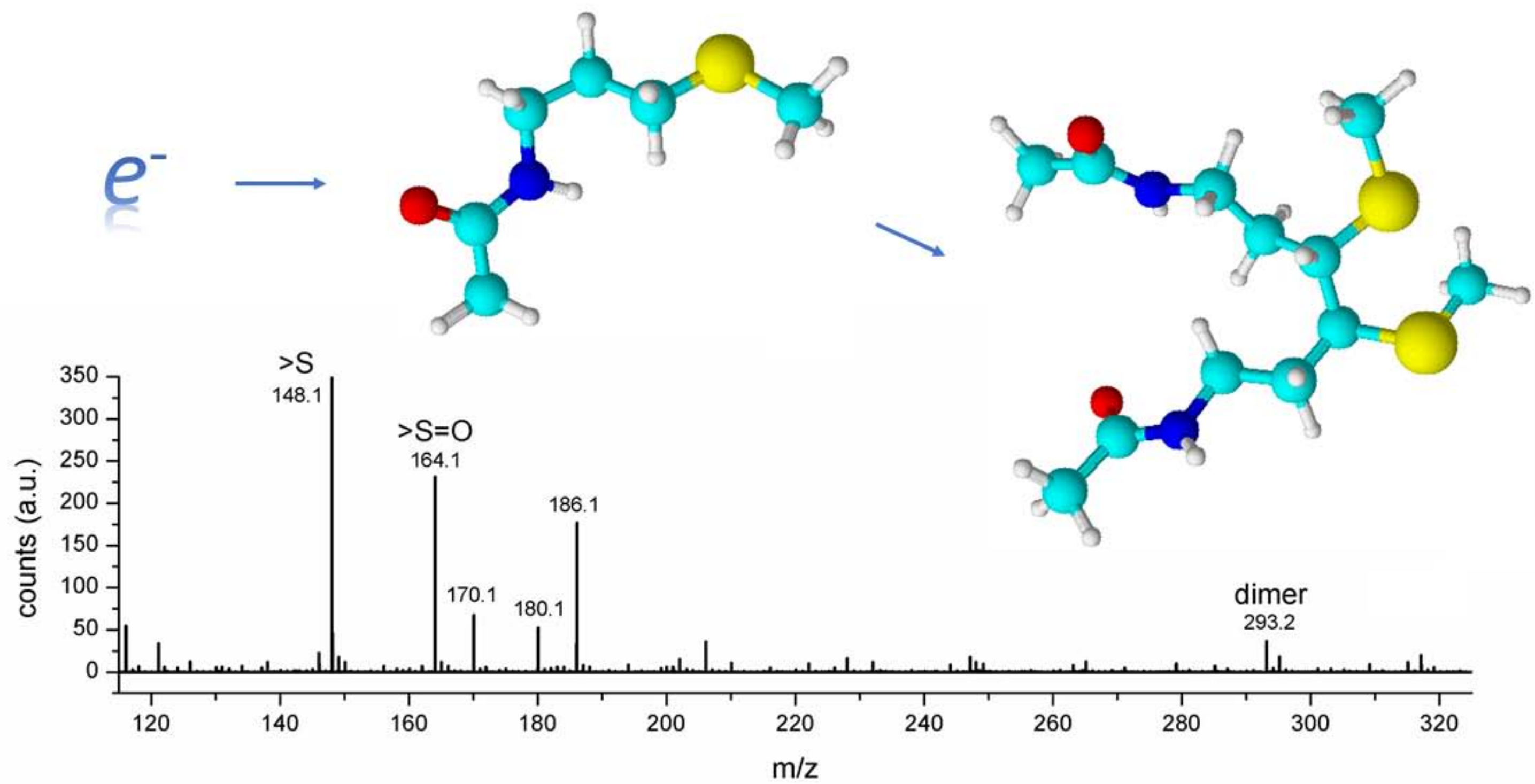

